\title{
Radio Broadcasting Experience and Development Prospects (European Scientific Dialogue)
}

\author{
Vadim A. Ryazantsev, Andrey V. Polonskiy, Irina I. Karpenko, Elena I. Radchenko and \\ Svetlana M. Narozhnyaya
}

Belgorod State University, 308015, Belgorod, Pobedy str., 85, Russia

\begin{abstract}
The paper presents an analysis of various opinions concerning radio-industry development issues, given new IT processes implemented in mass media. The authors study the technological evolution of radio broadcasting in terms of analyzing its main development stages. They provide an assessment of listeners' high confidence in radio broadcasts as compared to other mass media sources. Focus is placed on promoting sonic brands in the sphere of mediacommunication. The researchers also pay special attention to podcasting as a new way to listen to audio-content. The advantages and possible consequences of podcasting influence on radio-industry are assessed. The research is based on the expert discussion on radio broadcasting issues which took place at "Radiodays Europe 2019".
\end{abstract}

Keywords: European scientific dialogue, Internet technologies, digital format, radio broadcasting, broadcasting, voice assistant, podcasting, audio-brand.

\section{INTRODUCTION}

Radio is a key element of contemporary national media systems. Being available to various types of listeners, virtually crossing any barriers, it has developed into an indispensable element of contemporary culture. Broadcasting media industry is now changing rapidly, as it is directly involved in the globalization of IT. Specialists in the theory and practice of mass media face the need to assess the prospects and long-term longevity of conventional radio technologies. This step is important due to several reasons, namely: a growing number of people switching rapidly to digital media; expanded use of IT in the life of the society on the whole and individuals in particular, which does not even require any special tools today; and the Internet developing into the largest media segment of the advertising market, the latter depending on small and medium advertising customers.

Numerous specialists representing information policy and mass communication spheres, as well as socio-political, cultural, marketing and media research, have sufficient grounds to claim that despite persistent skepticism, radio remains one of the most popular channels of social communication and "the major stronghold in the world of sound which is becoming more and more diverse, both in analogue and digital sectors" (Mai, Meinzer and Schröter 2019: 406). According to Ya.N. Zasursky, "mass communication

*Address correspondence to this author at the Belgorod State University, 308015, Belgorod, Pobedy str., 85, Russia; E-mail: Polonskiy@bsu.edu.ru today is mostly represented with radio broadcasting which has received new incentives due to the development of satellite communication and the Internet, thus becoming virtually ubiquitous. The Internet enables us to listen to the radio of different and distant countries, while the development of satellite communication and digital broadcasting makes it possible to establish radio stations efficiently in various parts of the world" (Zasursky 2005). The Internet has become a powerful tool that the radio industry can use to transform broadcasting and to expand its scope and content.

The importance of our study may be explained with the need to reconsider the specifics of radio functioning in contemporary European national systems, given a new communication and information environment. This approach will reveal the factors which define the key trends and mainstream changes in the radio broadcasting industry.

In making social and marketing forecasts about the "radio of the future" project and the influence of the socalled "digital habits", two significant facts must be taken into consideration. These facts provide evidence of sustainable positive dynamics and include the following: (1) being a reliable, the most adaptive and quick way to render general messages, news, tutorial, musical and entertainment content to target audiences, radio broadcasting is among the society's life spheres which are of strategic importance, and it is aimed at full-scale and round-the-clock informing of the population; (2) given the new technological and social circumstances we are facing today for several reasons, numerous surveys have shown that radio is gaining 
more and more popularity in all European countries among various age groups, including the young generation. According to B. Domenichini, $99 \%$ of German population have access to at least one gadget with $\mathrm{FM}$ radio, 96\% have individual devices with music players and $93 \%$ have access to gadgets enabling podcast listening (Domenichini 2020: 53).

The "Multimedia-holding", a Russian radio broadcasting company which is among Russia's largest media holdings, has surveyed changes in the listeners' radio-content consumption patterns. Over 36\% of respondents say that they tend to listen to radio programs more than usual, while $60 \%$ claim that their radio content consumption patterns have not changed much. Research conducted in other European countries confirms this sustainability. For instance, Broadcast Programming \& Research consulting company has studied radio consumption in Germany, with findings indicating an expansion of radio content in the information space of various audiences (Eidelman 2020).

These findings are hard to disagree with, given the fact that among radio consumers is the so-called "creative class" mentioned by R. Florida in his papers (Florida, 2010). The scholar describes "the clustering of human creativity and talent" as "the powerful economic gains that come when smart and talented people locate near one another" and "the major force that animates great cities and urban areas", adding that "innovation, economic growth, and prosperity occur in those places that attract a critical mass of top creative talent" (Florida 2010).

Another indisputable fact is that there are "digital natives" (Prensky 2001). or "The Net Generation" (Jones 2010). They demand a high-speed Internet and $\mathrm{Wi}-\mathrm{Fi}$ access. In terms of radio content consumption, they show a sustainable preference for mobile streaming.

The objective of this study is to systematize the contemporary discussion of traditional radio broadcasting issues, as well as to analyze the opinions expressed by researchers and journalists at various expert platforms.

\section{Research Scope and Timeliness}

Mass media have always attracted special attention of researchers, as it is a form of communication practice which develops in the context of the society's cultural, ideological and technological projects. It has become an object of study for many contemporary Russian and European authors (Bolotova 2005; Hallin and Mancini 2004; Karpenko 2009; Korochensky, Srybnyy and Tyazhlov 2019; Lessig 2004; Palfrey and Gasser 2008; Polonskiy 2019; Ryazantsev 2008; Scott 2011), who analyzed significant parameters of various media-technologies and their development prospects in the context of the Internet's new information and communication environment.

To understand the way the radio-segment of contemporary European national media systems works, to identify the factors defining the industry's key trends and changes, and to amend mass-media strategies and prepare for the future, we need to resume the discussion concerning the well-established agenda of radio broadcasting. We also need to systematize and analyze opinions expressed by the academic community and mass-media community representatives at various discussion platforms.

The subject of the research is experts' discussion of radio broadcasting issues which took place at "Radiodays Europe 2019" international scientific conference in Lausanne. It is the largest European forum aimed at a broad exchange of opinions between the academic community and Europe's main radio stations with a view to a building a multi-faceted comprehension of key issues of the contemporary radio industry and its development prospects.

Among the conference speakers were Paul Keenan (CEO, Bauer Media UK and European Radio, UK), Dino Sofos (BBS Radio 5 Live, UK), Thomas Laufersweiler (Head of content ARD.de, Germany), Darren Davis (President, iHeartMedia Networks Group, USA), Jo McCrostie (Creative Director, Global, UK), Mark Little (CEO, Kinzen, Ireland), Tamar Charney (Managing Director, Personalization and Curation, NPR, USA), Brenda Salinas (News on the Assistant, Google, UK), Mustafa Isik (CEO, Kerngedanke, Germany), Ezra Eeman (Head of Digital, EBU Media Department, Switzerland). Besides, at the meeting of the radio industry representatives, the floor was given to Thomas Buch Andersen (Editor in Chief, DR 1 and radio news, Denmark), James Cridland (Editor of Podnews.net, Australia) and Grant Blackley (CEO, Southern Cross Austereo, Australia). Sibyle Veil (Radio France CEO), Noel Curran (DG of Swiss EBU), Ben Chapman (Head of digital for BBC Radio and Music, U.K) and Thomas Kabke-Sommer (managing director of Germany's Crossplan Deutschland) also shared their opinions with the participants. 
The "Radiodays Europe" discussion panel enables the participants to exchange the experience that many generations have gained in organizing radio broadcasting. It is also a place for scientific discussions and the proliferation of productive ideas concerning the radio-industry operation. Apart from researchers and theoretical specialists, the forum discussions involve producers of European radio channels and holdings, engineering specialists and creative staff (sound engineers, reporters, radio presenters, brand managers etc). The motto of "Radiodays Europe" in 2019 ran as follows: "Sound matters. The Future of Audio".

We focus on the opinions, ideas and assessments expressed by the conference participants about radio broadcasting as a sonic culture phenomenon and European radio broadcasting companies' practices today.

It should be emphasized that the conference involving radio industry representatives was not open to public., Access to its video-and audio proceedings was provided on a commercial basis. Therefore, many of the phrases, ideas, quotes, analytical statements, commentaries and discussion fragments cited herein are based purely on the notes we took while listening to the speakers and workshop participants. Such examples are marked with $\left({ }^{*}\right)$.

\section{METHODS}

For this research, we have mainly used observation and description methods enabling the oral and graphic content of the speakers' messages to be recorded and perceived. We have analyzed our records of oral messages concerning a wide range of radio broadcasting issues (those pertaining to programming, marketing, content proliferation content etc) and obtained a general idea of the radio industry's condition and its prospects.

We have used the inductive method to generalize specific facts pertaining to radio broadcasting transformation which resulted from new ways of audiocontent consumption, such as the introduction of digital broadcasting, the emergence of voice assistants, expansion of podcast share and the use of new gadgets after the radio went online.

The historical method has made it possible to identify major transformation stages that the radio industry has gone through since it became a mass medium.

\section{RESULTS AND DISCUSSION}

The "Radiodays Europe 2019" forum and its multiformat workshops raised issues connected with understanding the essence and specifics of audio culture in terms of radio operation, and its development prospects surrounded by various "smart" applications. A retrospective view of the radio industry enables us, among other, to take "a fresh look" at the radio and to understand how close are the new digital practices which are now expanding their presence in the society.

Throughout its history, radio broadcasting as an audio method of providing media products has faced quite a few transformation phases. Still, each of them has been significant and exerted influence on content consumption specifics.

At the first stage, in 1920s, radio was a "mass" medium of transmitting information for quite a short term. Its "mass" character meant that radio programs (news releases, theatre performances, popular science talks etc) were broadcast in public places via the socalled loudspeakers in real-time, as there were no technical means for speech recording.

The next stage of radio history was connected with the invention of a portable radio-set in mid-1920s. Radio was now available at homes, which added some intimacy to the listening process and enhanced trust in it. In the late 1920s, car radios were invented. Radio became transportable.

Probably, the last significant change that audio culture underwent in the last century was the possibility to record sound on tapes and the introduction of this technological breakthrough in radio broadcasting. This development paved the way for changes in the semantic content, radio drama and consumption conditions: the audience received the opportunity to listen to programs of various genres at any time convenient.

For quite a long time, the radio broadcasting pattern included two participants: a radio-set and a listener. Gradually, methods and platforms of radio content consumption have changed. Tamar Charney, Managing Director of NPR (US), describes this transformation as applied to the contemporary radio industry, connecting it with the penetration of computer technologies into our lives: thus, an Electronic Computing Machine was a technical mediator in information processing in 1977, while in 1987 this role was performed by a Personal Computer. In 2007, a 
mobile phone was the main tool of media consumption, and in 2017 a voice assistant became an intermediary between people and mass-media. This is the way media content consumption platform has changed for the past 40 years.

We must stress that voice recognition technology had been developed long before Apple Siri made its debut in 2011. At the 1962 Seattle World's Fair, IBM displayed the Shoebox. This computer was the size of a shoebox, it performed mathematical functions and was able to recognize 16 spoken words and digits 0 through 9. Following that, in 1970s, a connected speech recognition system known as Harpy was developed at Carnegie-Mellon University. It was able to recognize as many as over 1, 000 spoken words.

The next step in voice recognition technologies was the development of applications useful in our everyday life. For instance, George Doddington's toys development project at Texas Instruments produced interactive talking Julie Doll, the first of its kind. It had a built-in DSP processor enabling the toy mechanism to recognize and generate speech.

In 1990s, the idea of designing a voice assistant for practical purposes gained a new impetus. Due to improvements in the IT-sphere, major companies were able to present voice recognition products in the hi-tech market. In 1993, Apple began to preinstall voice recognition functions in Macs, using the Plain Talk assistant. In 1997 Dragon Systems released its DNS (Dragon Naturally Speaking), a first continuous dictation product which understood about 100 words per minute and transformed them into a text.

In 2000s, major companies were introducing their developments in PCs and various portable devices and gadgets. In 2001, Microsoft Office XP was supplied with a voice search function. In 2002, Google launched Voice Search feature was later used as a basis for Google Assistant. In 2007, SRI International began working at the Siri project, completing it by 2011. After three years of research, in 2014 Google integrated voice search feature into Google Chrome browser. They also introduced Google Now personalized assistant. In the same year, Amazon introduced the first "intelligent" voice-controlled loudspeaker supplied with Alexa voice service. In 2017, a similar "smart" speaker known as was Tmall Genie was launched by Alibaba. It had AliGenie voice search feature. In 2018 Russia's Yandex produced its smart speaker, "Yandex.station", with Alisa voice assistant.
In April, 2020, Russia's Mail.ru Group launched the sales of its "Capsule" smart speaker with Marusya voice assistant. Among the exclusive advantages is the possibility to make phone calls in Vkontakte.ru social network. GPS function is also preinstalled in Capsule, though, the Russian "Vedomodsti" newspaper believes this application has a poor sense of direction, as compared to Yandex.station (Kodachigov 2020). Still, Marysya recognizes clear voice commands quite well and follows the instructions in detail. It can search for information and entertainment content, including music, and switch on the radios available on the Internet.

According to Naked Science (Naked-science.ru), scholars of Carnegie Mellon University have introduced their "Digital ventriloquism" project. It is a prototype system capable of switching on several microphones and a videocam to control the environment. Using videocams, the device identifies objects and modulates $40 \mathrm{kHz}$ ultrasonic signals inaudible for people. The sound signal reflected from the objects is demodulated, rendering "voice" to them. The production launch date is still unknown, though engineers have already shown what it will look like in everyday use.

Today voice assistants are implemented in various media spheres, enabling technological contact between consumers and media content to take place. For instance, National Public Radio is trying to adopt a personalized approach using a voice assistant, thus enabling listeners to manage the podcasts. Listeners may come home, switch on the voice assistant, search for the necessary NPR podcast about culture, sports or business news, politics, weather forecast etc. According to Tamar Charnie, NPR Managing Director, it is a new information consumption pattern. Hence, traditional broadcasting is now becoming integrated into new media outlets, while information or music content may be additionally broadcast on alternative platforms.

According to Mediascope, as of $2018,30 \%$ of radio content consumers used various Internet resources and services for this purpose. People used smartphones, Smart-TV, tablets and laptops to listen to the radio online (Mediascope 2018). It is evident that with further development of the digital environment the number of such listeners will grow. However, media companies are not ready to switch to online broadcasting format in full. First, Internet broadcasting does not meet the requirements of regional commercial airtime, as the advertising market varies in different regions. It depends on the social, economic, demographic situation and development level in 
respective regions of Russia. Second, at some point in the future Russia will have to switch to digital radio broadcasting. Though this step may be painful for radio advertising, it is a natural trend of the world radio industry. Radio digitalization will open new audio content consumption opportunities, including technological ones. To this end, technical and legal issues must be solved: statutory acts need to be developed, radio transmitters need to be re-equipped, sales of new DAB+ receivers need to be launched, a broad campaign is necessary to provide listeners with expanded access to all media vehicles, and digital car radio should be installed in motor vehicles.

Besides, several years must pass before the number of digital radio listeners returns to the level of analogue radio audiences. WorldDAB, which is a global digital radio forum contributing to $D A B / D A B+-$ based introduction of digital radio, cites the results of Norway's digital broadcasting experience. It was not until 2019 that the radio audience numbers returned to the level of 2016, when the country's radio went digital. Last year daily radio outreached $67 \%$ of the population, while in 2016 this number equaled to $68 \%$. In 2019 , people listened to the radio for 146 minutes a day on average, while in 2016 it took them 127 minutes. Listeners who use $\mathrm{DAB}+$ daily represent $86 \%$ of the population, compared to $55 \%$ in 2016 . Besides, the number of cars with $\mathrm{DAB}+$ car radio systems has increased. Today $98 \%$ of the cars sold in Norway have preinstalled $\mathrm{DAB}+$ car stereos. Rachel Staviskaya, $\mathrm{PhD}$ in Engineering and member of the International Informatization Academy quotes the world statistical data on digital radio consumption. She says that last year the number of cars with preinstalled DAB+ amounted to about 2 million 470 thousand. The scholar expects this number to reach 3 million 930 thousand cars in 2021.

We would like to stress that among the advantages of digital radio is an enhanced quality of the content transmitted (the sound quality). The same result may be achieved by placing audio content on other online platforms. The audience will consume a higher quality of the product without broadcasting going digital.

According to Olga Mikhailova, Head of Russia's GPM Radio Digital Department, radio integration in digital services makes it possible to achieve additional listeners' loyalty and opens up new monetization opportunities. She believes podcasting to be an ideal and natural process of content consumption transformation, from the monetization perspective.
When listeners activate one or another podcast using voice assistants or choose the necessary ones on the Internet, they do it intentionally, allowing listening time. Chances are high that they will be better involved in the listening process and will pay more attention to commercials.

According to Ezra Eeman of the European Broadcasting Union, smart voice-controlled speakers have quickly penetrated into our everyday lives, becoming a means of interaction between consumers and the media. They do not seem to be anything extraordinary. Five years ago, we knew nothing of Amazon Echo or Google Home. Today voice control feature is so wide-spread that futurologists forecast its presence in all appliances, from cars to fridges, on the one hand, and fear keyboards may become extinct as an obsolete means of text-typing, on the other. Mass media experts are cautious in their assessment of new devices being used in the radio industry. They believe voice assistants may both contribute to media development in the short-term perspective and complicate interaction between radio stations and their audiences.

Today we are witnessing the emergence of new methods to create and listen to radio content. In the first place, it concerns podcasting. Podcasts are popular due to their interactive character. First of all, listeners have a freedom of choice which has not been offered by any mass medium so far. They can find what they need and what is unavailable in traditional radio channels. Second, among the biggest podcast advantages is the opportunity to choose programs, news and music tracks. In other words, it is the Radio on Demand technology come true. Third, podcasting enables listeners to author their own programs, giving them self-fulfillment opportunities at little cost. It cannot be denied that the trend results in numerous poorquality podcasts, both in terms of artistic and technical quality. The very fact that new content consumption methods are emerging can mitigate two significant features inherent in radio. First, what expert describe as content presentation simultaneousness disappears in this case. The standard pattern of planning the running order is no more applied, and listeners can decide for themselves when they will listen to one or another program. It entails the disappearance of another permanent feature, which is fixed-time broadcasting. In fact, podcasts are meant to eliminate the above two features. Ezra Eeman believes we are far from the latter scenario, though he agrees that audiences tend to choose audio consumption of media 
content over visual one, which offers direct access. It mostly results from the fact that media consumption is becoming convenient and comfortable in any situation, whether you are driving, cooking, doing sports, breastfeeding or tidying up. This may entail certain risks if people start choosing such devices to consume any other audio content. In this case, radio content consumption will no longer be sustainable. That is why the radio industry should not leave smart speakers unnoticed.

Simon Gooch, Chief Innovation Officer at Swedish Radio, says that it has become easier to consume the sound. He believes we are consuming more sound than ever and adds that it may result from voice assistants' popularity and better availability of wireless earphones (RDE 2019). This is why radio channels abandon classical text format of the news presented at the websites, suggesting alternative content instead and trying to individualize it, that is, making playlists more convenient in terms of relevant news search. In this context, it is vital that radio stations offer various levels of listeners absorption in one or another piece of news, depending on thematic, territorial or temporal principles.

According to Simon Gooch, Swedish radio today is focused on developing their own audio consumption platform, an application enabling the content to be systematized, access simplified and adding the feature of listening within specific time frames.

There is no doubt that the trust level between the radio industry and its audiences is significant. According to Darren Davis, "trusted voices create deeper bonds with listeners" (RDE 2019). Some experts claim that people's trust in all mass media is declining, though trust in radio is stronger than that on TV and the Internet. According to Noel Curran, DG of the EBU, "radio's still by far the most trusted medium in Europe", with $85 \%$ of Europeans trusting it. The speaker stressed that it is possible to "maintain our trust levels if we continue to invest in our programming and our journalism" and also "if we maintain our connection with our audience by being available to them where and when and how they need us" (RDE 2019). He said that radio "has faced the biggest crisis in audience trust in media history and is still coming out on top" and called the participants "to keep the original electronic medium fresh and engaging" (RDE 2019). Darren Davis considers the condition of the radio industry as quite sustainable, saying "Radio is a companion. Television is a hobby. You swap hobbies much more often than you do companions" (RDE 2019).

As we are speaking about radio as an audio means to transmit content, the issue of audio branding in contemporary radio industry deserves attention. According to Jo McCrostie, the Creative Director at Global UK, only in Great Britain as few as $17 \%$ of companies invest in audio branding, while the majority of the market players do not have any distinctive brand sound, or "voice". The speaker stresses that $86 \%$ of advertising customers have properly designed visual brands, logos, colours and fonts. At the same time, some of the UK's leading companies engaged in digital technologies do not have their own voices, which is why they find it difficult to advertise in audio mass media, for instance, on the radio. Jo McCrostie notes that the majority of brands today are mute, they have no sound. According to the speaker, it is important to understand the difference between mute brands and those which invest in audio but fail to have their own voices. She says many brands may have emotional music and voice in commercials, but it does not mean that it is their own voice, adding that "if a brand does not have a voice, it is lagging behind" (RDE 2019). McCrostie also pays attention to the fact that increasing penetration of voice assistants into our everyday lives via various means, including mobile phones, will enable verbal communication to take place between people and Al-based services.

The society, and hence the media sphere, are increasingly consuming the sound. According to Jo McCrostie, "Sound is becoming more important than images for brands" (RDE 2019). That is why each brand should have a voice identity, just like people do. Today there are tried-and-true platforms which can proliferate such "voice", that is, the radio industry. New technologies for transmitting a brand voice is one of the technological alternatives.

\section{CONCLUSION}

The discussion of key issues at the conference enables us to conclude that overall development strategy of contemporary radio industry includes such aspects as sound in its broad sense, sound consumption methods, voice assistant and its shortterm influence on radio broadcasting and consequently, content broadcasting amidst simplified audio content proliferation. It is evident that the radio industry which has successfully gone digital will have to adapt to the emergence of new platforms and forms of audio 
content consumption. The positive aspects of such developments include radio industry's awareness of the consequences and the adaptability and flexibility of European radio stations.

\section{REFERENCES}

Bolotova, L. D. 2005. Domestic radio broadcasting early in the XXI century the new realii and old problems. From: TV- and radio broadcasting: history and our days. Ed. YaN. Zasursky. Moscow: Aspekt Press, 239 p.

Domenichini, B. 2020. Radio, Musik und Podcasts im digitalen Transformationsprozess. Media Perspektiven, 2, 53-61.

Eidelman, M. People increasingly listen to the radio despite the pandemic. CIS Media Solutions. April 5, 2020 Retrieved from: http://cismedia.ru/2020/04/slushanie-radio-rastetnesmotrja-na-pandemiju/

Florida, R. 2010. The Flight of the Creative Class. The New Global Competition for Talent. Harper Business, Harper Collins, 352 p.

Hallin, D.C., \& Mancini, P. 2004. Comparing Media Systems: Three Models of Media and Politics. England: Cambridge University Press, $358 \mathrm{p}$ https://doi.org/10.1017/CBO9780511790867

Jones C., \& Healing G. 2010. Net generation students: agency and choice and the new technologies. Journal of Computer Assisted Learning, 26 (5): 344-356. https://doi.org/10.1111/j.1365-2729.2010.00370.x

Karpenko, I.I. 2009. Radio broadcasting in the Internet: broadcasting forms, specifics of journalists' professional activities and new development trends. Voronezh: Voronezh State University Bulletin, Series: Philology, Journalism, 1: 150-158.

Kodachigov V. (2020). What is hidden in the "Capsule". Vedomosti, 828850. Retrieved from: vedomosti.ru/technology/articles/ 2020/04/23/828850-chto-spryatano-v-kapsule. Accessed on 23 April, 2020

Korochensky, A. P., Sribny, D.S., Tyazhlov, Ya.I. 2019. Civil Media Criticism and Political Processes in Mediatized Society. Media-education. Bratislava, Academic Publishing House Researcher s.r.o. 59 (3): 393-399. https://doi.org/10.13187/me.2019.3.393
Lessig, L. 2004. Free Culture: How Big Media Uses Technology and the Law to Lock Down Culture and Control Creativity / Lawrence Lessig. London, Penguin Press, 345 p.

Mai, L., Meinzer, N., \& Schröter, Ch. 2019. Radio- und Audionutzung 2019. Media Perspektiven, 9: 406-420.

Mediascope: The radio audience in Russia. Mediascope. 2018, October 9. Retrieved from: http://mediascope.net/news/ 819431/).

Palfrey, J., \& Urs, G. (2008). Born Digital. Understanding the first generation of digital natives. New York, $288 \mathrm{p}$.

Polonskiy, A.V. 2019. Media linguistics: the contemporary paradigm of scientific knowledge. Review of a reference-book: "Duskayeva, L.R., 2018, (Ed.) Media linguistics in terms and concepts. Moscow: Flinta: Nauka". Media Almanach, 1, 206211. DOI: 10.30547/mediaalmanah.1.2019.206211. Retrieved from: http://www.mediaalmanah.ru/files/90/616.php

Prensky, M. 2001. Digital natives, digital immigrants. From On the horizon, MCB University Press, 9(5), 1-6. https://doi.org/10.1108/10748120110424816

RDE 2019 - Radiodays Europe. 31 March - 02 April 2019. Lausanne Switzerland.

Ryazantsev, V.A. 2008. Communicative and cultural components and mechanisms of a commercial music radio image-making: a case study of Belgorod radio stations. $\mathrm{PhD}$ thesis in Philology, 10.01.10 field of study. Belgorod: Belgorod State University: $181 \mathrm{p}$

Scott, M. 2009. Guidelines for broadcasters on encouraging media and information literacy and user-generated content. London: CBA, 61p

Vasiliev S. 2020. Digital "ventriloquism" will supply any domestic objects with a voice assistant. Retrieved from: https://nakedscience.ru/article/hi-tech/tsifrovoe-chrevoveshhanie-dopolnitgolosovym-pomoshhnikom-lyubye-predmety-v-dome (accessed on 21.04.2020).

Zasursky, Ya.N. 2005. The most transparent information source. TVand radio broadcasting: history and our days. Ed. Ya.N. Zasursky. Moscow: Aspekt Press, 146 p.

\section{DOI: https://doi.org/10.6000/1929-4409.2020.09.128}

(c) 2020 Ryazantsev et al.; Licensee Lifescience Global.

This is an open access article licensed under the terms of the Creative Commons Attribution Non-Commercial License (http://creativecommons.org/licenses/by-nc/3.0/) which permits unrestricted, non-commercial use, distribution and reproduction in any medium, provided the work is properly cited. 